\title{
Characterization of Plp, a phosphatidylcholine- specific phospholipase and hemolysin of Vibrio anguillarum
}

Ling $\mathrm{Li}^{1,2+}$, Xiangyu Mou ${ }^{1,3+}$ and David R Nelson ${ }^{\text {* }^{*}}$

\begin{abstract}
Background: Vibrio anguillarum is the causative agent of vibriosis in fish. Several extracellular proteins secreted by $V$. anguillarum have been shown to contribute to virulence. While two hemolysin gene clusters, vah1-plp and rtxACHBDE, have been previously identified and described, the activities of the protein encoded by the plp gene were not known. Here we describe the biochemical activities of the plp-encoded protein and its role in pathogenesis.

Results: The plp gene, one of the components in vah1 cluster, encodes a 416-amino-acid protein (Plp), which has homology to lipolytic enzymes containing the catalytic site amino acid signature SGNH. Hemolytic activity of the plp mutant increased 2-3-fold on sheep blood agar indicating that plp represses vah1; however, hemolytic activity of the plp mutant decreased by 2-3-fold on fish blood agar suggesting that Plp has different effects against erythrocytes from different species. His 6 -tagged recombinant Plp protein (rPlp) was over-expressed in E. coli. Purified and re-folded active rPlp exhibited phospholipase A2 activity against phosphatidylcholine and no activity against phosphatidylserine, phosphatidylethanolamine, or sphingomyelin. Characterization of rPlp revealed broad optimal activities at pH 5-9 and at temperatures of $30-64^{\circ} \mathrm{C}$. Divalent cations and metal chelators did not affect activity of rPlp. We also demonstrated that Plp was secreted using thin layer chromatography and immunoblot analysis. Additionally, rPlp had strong hemolytic activity towards rainbow trout erythrocytes, but not to sheep erythrocytes suggesting that rPlp is optimized for lysis of phosphatidylcholine-rich fish erythrocytes. Further, only the loss of the plp gene had a significant effect on hemolytic activity of culture supernatant on fish erythrocytes, while the loss of $r$ txA and/or vaht had little effect. However,

$V$. anguillarum strains with mutations in plp or in plp and vah1 exhibited no significant reduction in virulence compared to the wild type strain when used to infect rainbow trout.

Conclusion: The plp gene of $V$. anguillarum encoding a phospholipase with A2 activity is specific for phosphatidylcholine and, therefore, able to lyse fish erythrocytes, but not sheep erythrocytes. Mutation of plp does not affect the virulence of $V$. anguillarum in rainbow trout.
\end{abstract}

Keywords: Vibrio anguillarum, Vbriosis, Phospholipase, Hemolysis, Virulence

\section{Background}

Vibrio anguillarum, a highly motile marine member of the $\gamma$-Proteobacteria, is one of the causative agents of vibriosis, a fatal hemorrhagic septicemic disease of both wild and cultured fish, crustaceans, and bivalves [1]. Fish infected with $V$. anguillarum display skin discoloration and erythema around the mouth, fins, and vent. Necrotic lesions are also observed in the abdominal muscle [2].

\footnotetext{
*Correspondence: dnelson@uri.edu

†Equal contributors

'Department of Cell and Molecular Biology, University of Rhode Island, 120

Flagg Rd., Kingston, RI 02881, USA

Full list of author information is available at the end of the article
}

Mortality rates in infected fish populations range as high as $30-100 \%[1,3]$. Vibriosis has caused severe economic losses to aquaculture worldwide [1,3] and affects many farm-raised fish including Pacific salmon, Atlantic salmon, sea bass, cod, and eel $[3,4]$. V. anguillarum enters its fish host through the gastrointestinal tract (GI) and quickly colonizes this nutrient rich environment [2,5]. Garcia et al. [6] have shown that $V$. anguillarum grows extremely well in salmon intestinal mucus and that mucus-grown cells specifically express a number of different proteins, including several outer membrane proteins [6] and the extracellular metalloprotease EmpA [2,5]. 
Several genes have been reported to be correlated with virulence by $V$. anguillarum, including the vah1 hemolysin cluster [7,8], the $r t x$ hemolysin cluster [9], the siderophore mediated iron transport system [10], the empA metalloprotease [2,5], and the flaA gene [11]. Hemolytic activity of $V$. anguillarum has been considered to be the virulence factor responsible for hemorrhagic septicemia during infection [10]. We have identified two hemolysin gene clusters in $V$. anguillarum that contribute to the virulence of this pathogen [8,9]. One gene cluster, $r t x A C H B D E$, encodes a MARTX toxin and its type I secretion system [9]. The second hemolysin gene cluster in $V$. anguillarum strain M93Sm contains the hemolysin gene vah1 flanked by two putative lipase-related genes (llpA and $l l p B$ ) immediately downstream and upstream by a divergently transcribed hemolysin-like gene $(p l p)$ that appears to function as a repressor of vah1-dependent hemolytic activity [8]. The $p l p$-encoded protein has very high sequence similarity to phospholipases found in other pathogenic Vibrio species [8]. However, the enzymatic characteristics of Plp in $V$. anguillarum were not described.

Generally, phospholipases are divided into several subgroups depending on their specificity for hydrolysis of ester bonds at different locations in the phospholipid molecule. Phospholipases A (PLAs) cleave long chain fatty acids at sn-1 (PLA1) or sn-2 (PLA2) position from phospholipid to yield lysophospholipid and free fatty acid; phospholipases C (PLCs) cleave phospholipid into diacylglycerol and a phosphate-containing head group; and phospholipases D (PLDs) cleave phospholipid into phosphatidic acid and an alcohol. It is known that some phospholipid products are used as secondary messages, which play a central role in signal transduction [12].
In this study, we determined that $p l p$ encodes a phospholipase A2 in $V$. anguillarum, and then purified recombinant Plp protein ( $\mathrm{rPlp}$ ) from $E$. coli to investigate its biochemical properties. We also described the contribution and specificity of rPlp for hydrolysis of phospholipids, and its ability to lyse fish erythrocytes.

\section{Results}

\section{Identification of a putative phospholipase gene plp}

Previously, a putative phospholipase gene, $p l p$, was identified in the vah1 hemolysin cluster of $V$. anguillarum strain M93Sm [8]. The 1251-bp plp gene (Genbank accession EU650390) was predicted to encode a protein of 416 amino acids. A BLASTx [13] search revealed that the deduced Plp amino acid sequence exhibited homology with many lipolytic enzymes including the phospholipase/lecithinase/hemolysin of Vibrio vulnificus (identity, 69\%; similarity, 82\%); the lecithin-dependent hemolysin (LDH)/ thermolabile hemolysin (TLH) of Vibrio parahaemolyticus (identity, 64\%; similarity, $80 \%$ ); the lipolytic enzyme/hemolysin $\mathrm{VHH}$ of Vibrio harveyi (identity, 63\%; similarity, 78\%); and the thermolabile hemolysin of Vibrio cholerae (identity, 62\%; similarity, $78 \%$ ). The phylogenetic tree created by the Clustal-W program from $17 \mathrm{Plp}$ homologous proteins revealed that while the most closely related Plp proteins were all from pathogenic members of the genus Vibrio, the Plp of $V$. anguillarum was an outlier among the Vibrio species, as demonstrated by the Neighbor Joining analysis (Figure 1). According to Flieger's classification [14,15], the alignment of Plp with other homologous proteins indicated that Plp could be classified into subgroup B of this lipolytic family with its long $\mathrm{N}$-terminal tail (data not shown) prior to the
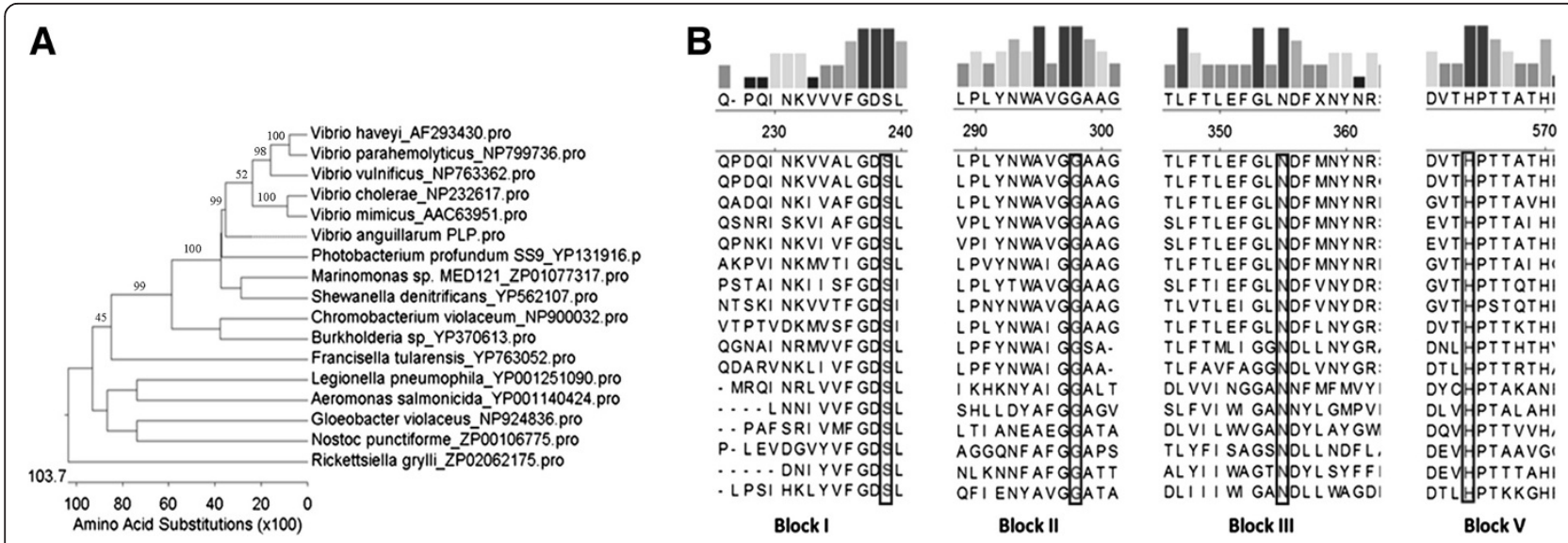

Figure 1 The phylogenetic tree (A) and amino acid sequence alignment (B) of $V$. anguillarum Plp with members of the SGNH family. The phylogenetic tree was analyzed by the Neighbor Joining (NJ) method with 1000 bootstraps, and node support values (as percentages) are labeled above the branch lines of the phylogenetic tree leading to the Plp homologues found in the genus Vibrio. Sequences of the 16 closest matches to PIp are aligned along the five conserved blocks of the SGNH family (Block IV not shown). The rectangle bars above the alignment indicate the amount of conservation of amino acid residues. The four residues conserved in all SGNH family members are boxed. 
block I [14]. Additionally, close examination of the amino acid sequences of these enzymes revealed that the typical GDSL motif for lypolytic enzymes is not totally conserved in all of these 17 proteins, in which leucines (L) are replaced with isoleucines (I) in Photobacterium, Marinomonas, and Shewanella (Figure 1). In this case, V. anguillarum Plp should be considered as a member of the SGNH hydrolase family, based on the Molgaard's suggestion that only four amino acids (, G, N, and $\mathrm{H}$ ) are completely conserved among the GDSL proteins [16].

\section{Plp affects hemolysis of fish erythrocytes}

The hemolysin gene vah1 is divergently transcribed from $p l p$ [17]. Mutation of $p l p$ increased hemolytic activity by 2-3-fold on Trypticase soy agar plus 5\% sheep blood (TSA-sheep blood) plate compared with wild type strain (M93Sm) (Figure 2A) [8]. Rock and Nelson [8] also demonstrated that the plp mutant had increased vah1 transcription (by 2-4-fold), indicating that Plp is a putative repressor of vah1. Previously, we demonstrated that a double mutant in vah1 and $r t x A$ resulted in a hemolysis negative mutant when plated on TSA-sheep blood agar [9]. Similar results were observed when using LuriaBertani broth plus 2\% $\mathrm{NaCl}$ plus 5\% sheep blood (LB20sheep blood) agar (data not shown). However, on LB20 plus 5\% rainbow trout blood (LB20-rainbow trout blood) agar, the $p l p$ mutant exhibited a smaller zone of hemolysis compared to wild type strain M93Sm (diameter: $9.5 \pm$ $0.5 \mathrm{~mm}$ vs. $12 \pm 0.0 \mathrm{~mm}, P<0.05$ ) (Figure $2 \mathrm{~B}$ ); complementation of $p l p$ restored the hemolytic activity of the mutant strain (Figure 2B). Similar results were observed when using LB20 plus 5\% Atlantic salmon blood agar (data not shown), suggesting that the ability of Plp to lyse

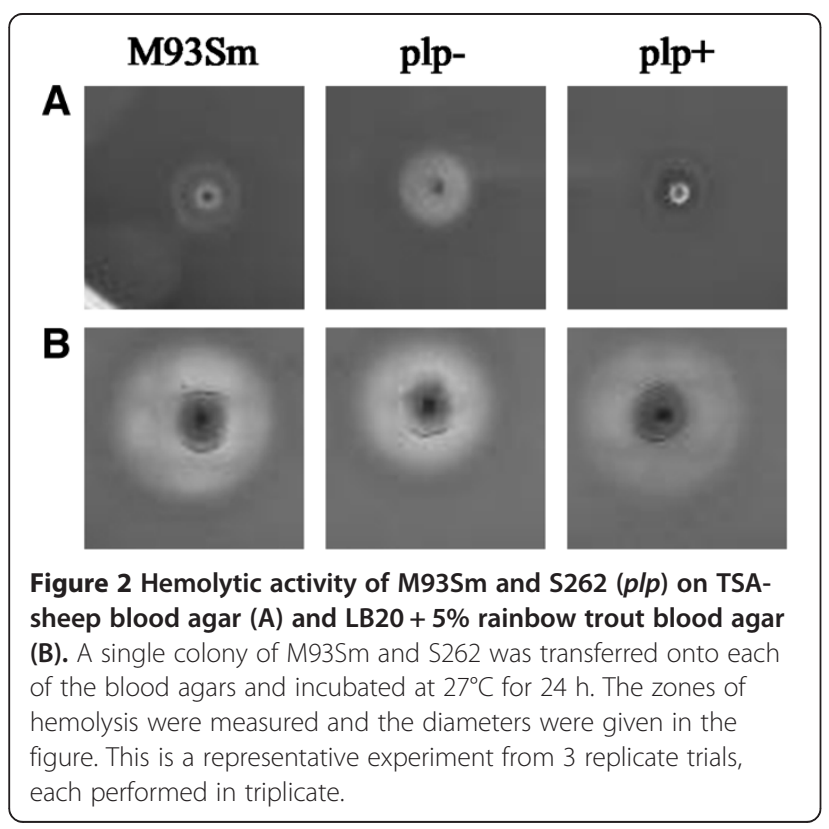

erythrocytes is dependent upon the source of erythrocytes and, therefore, their lipid composition.

\section{Plp has phospholipase A2 activity}

Thin layer chromatography (TLC) was used to examine the pattern of phospholipid cleavage by Plp. BODIPYlabeled phosphatidylcholine (BPC) was incubated with various enzyme standards, including phospholipase A2 (PLA2), phospholipase C (PLC), or phospholipase D (PLD). TLC analysis revealed distinct cleavage patterns (Figure 3A) by these standard enzymes indicating that BPC was an appropriate substrate to examine Plp activity. Cell lysate prepared from E. coli strain S299, which contains the shuttle plasmid pSUP202-plp that was able to complement the plp mutation in $V$. anguillarum [8], cleaved BPC to yield BODIPY-lysophosphatidylcholine (BLPC) (Figure 3B, lane 5) plus unlabeled free fatty acid (FFA) that is not detectable. The cleavage products were identical to those generated by PLA2 (Figure 3B) and demonstrate that Plp has phospholipase A2 activity. Additionally, the culture supernatant from S299 had only 5\% of the activity of that in cell lysate, indicating that Plp accumulated in the cell lysate instead of being secreted by the E. coli strain. No phospholipase activity was detected in PBS buffer or in E. coli DH5 $\alpha$ containing only the pSUP202 vector (Figure 3B). Further, phospholipase A2

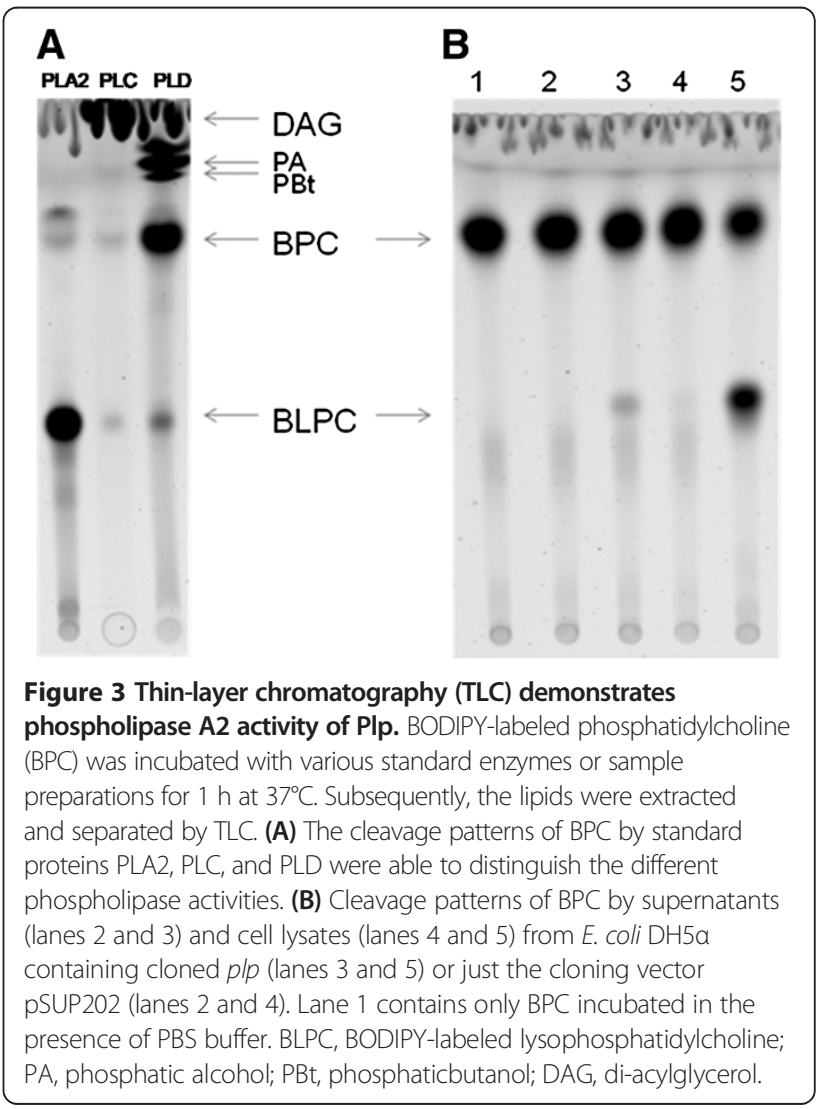


activity was examined in various subcellular fractions prepared from E. coli strain S299, including cytoplasm, cytoplasmic membrane, and outer membrane fractions. Most Plp activity was detected in Tween-20 soluble membrane fraction, indicating that Plp was mainly localized in the cytoplasmic membrane of E. coli S299 (data not shown). No BODIPY-labeled free fatty acid (FFA) (at sn-1 position) was detected in the TLC analysis when an apolar solvent was used (data not shown), and BODIPY-labeled LPC was not further degraded by Plp in the reaction, indicating that Plp had no lysophospholipase or phospholipase B activity.

\section{Enzymatic characteristics of rPIp protein}

To examine the enzymatic characteristics of Plp, the entire coding sequence of $p l p$ was cloned and inserted into the expression vector pQE60, which adds a $\mathrm{His}_{6}$ (His$6 \times)$ tag to the carboxyl end of Plp. The over-expressed recombinant Plp (rPlp) formed inclusion bodies in $E$. coli. To recover active rPlp, purification of the inclusion bodies followed by solubilization under mild conditions and re-folding was performed as described in the Methods. Purity of refolded rPlp protein was confirmed by SDSPAGE and silver staining (data not shown). The final concentration of purified rPlp protein was $8 \mu \mathrm{g} / \mathrm{ml}$ with a recovery of $<10 \%$.

Subsequently, the enzymatic characteristics of refolded rPlp were examined under various chemical and physical conditions. The enzymatic activity of $\mathrm{rPlp}$ positively correlated to its concentration from $1 \mu \mathrm{g} / \mathrm{ml}$ to $8 \mu \mathrm{g} / \mathrm{ml}$ (Figure $4 \mathrm{~A}$ ); therefore, $4 \mu \mathrm{g} / \mathrm{ml} \mathrm{rPlp}$ protein was routinely used in other activity assays. The enzymatic activity unit of refolded rPlp ( 1 unit = amount of protein that cleaves $1 \mu$ mole of BODIPY-PC per minute) was about 2,500-fold higher than standard PLA2 enzyme extracted from porcine pancreas, which indicated that Plp had a high activity against the BPC phospholipid substrate. Plp enzyme activity exhibited a broad temperature optimum from $37^{\circ} \mathrm{C}$ to $64^{\circ} \mathrm{C}$ (Figure 4B) with $75 \%$ activity retained at $27^{\circ} \mathrm{C}$ and $50 \%$ activity at $20^{\circ} \mathrm{C}$. While rPlp activity rapidly decreased at temperatures above $70^{\circ} \mathrm{C}$, the enzyme retained full activity at $64^{\circ} \mathrm{C}$ for at least $1 \mathrm{~h}$. The data demonstrate that $\mathrm{rPlp}$ is a relatively themostable phospholipase.

The effect of $\mathrm{pH}$ on enzyme activity was determined for $\mathrm{pH}$ values ranging from 2 to 12 . The data showed that $\mathrm{rPlp}$ had a broad $\mathrm{pH}$ optimum from $\mathrm{pH} 5.3$ to $\mathrm{pH} 8.7$ with activity dropping off rapidly at $\mathrm{pH}$ values above and below the optimum (Figure 4C). rPlp activity was not affected by treatment with the chelating reagents EGTA (Figure 4D) or EDTA (data not shown) at concentrations up to $100 \mathrm{mM}$. Additionally, treatment with divalent metal ions, such as calcium or magnesium had no effect on activity (data not shown).
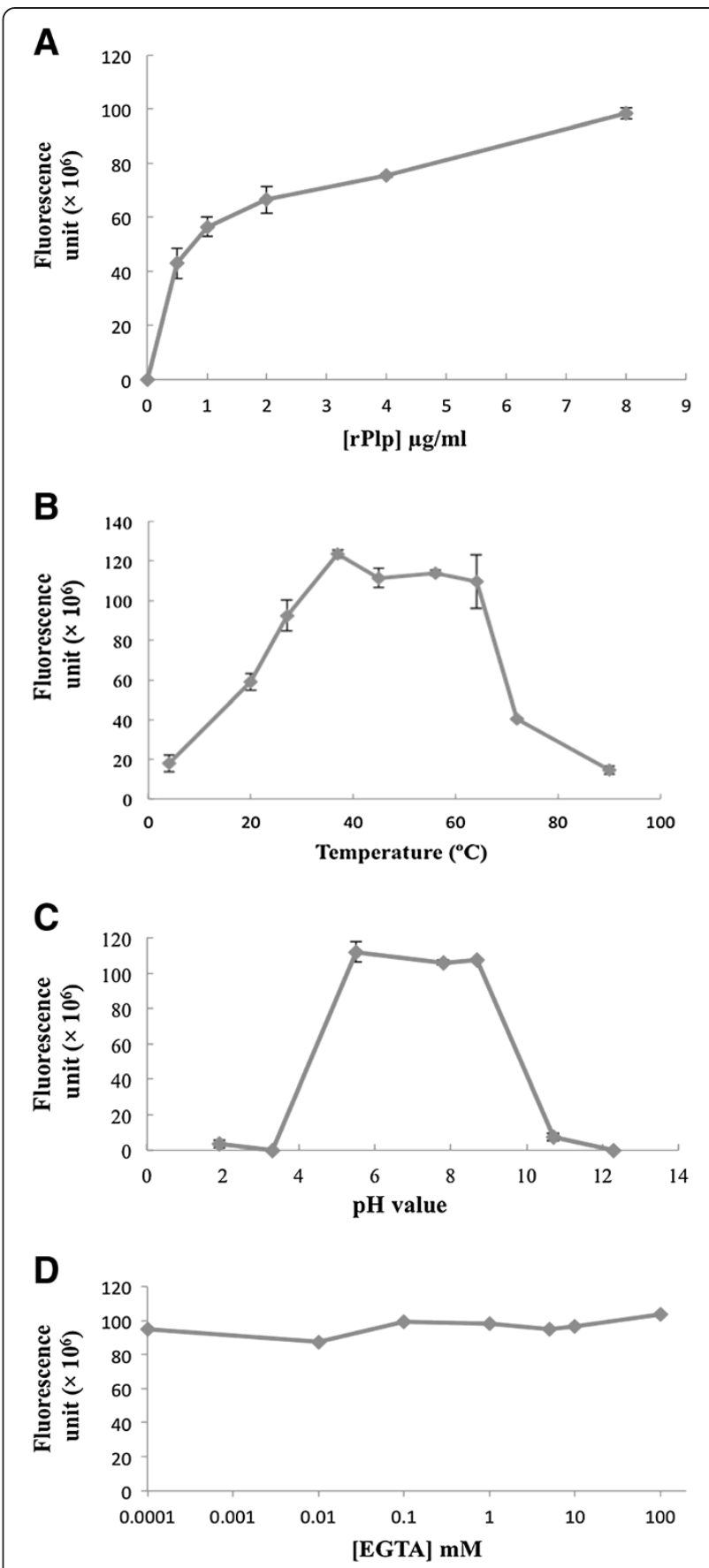

Figure 4 Effects of chemical and physical conditions on rPlp activity. (A) Effect of rPlp concentration on enzymatic activity. (B) The effect of temperature on rPlp activity. (C) The effect of pH on rPlp activity. (D) The effect of EGTA rPlp activity.

Plp is a secreted protein in V. anguillarum

Subcellular fractions from $V$. anguillarum strains M93Sm and S262 ( $p l p)$ were prepared and phospholipase A2 activity examined using BPC and TLC. Initial studies revealed that at $37^{\circ} \mathrm{C}$ phospholipase $\mathrm{A} 2$ activity was detected in all cell fractions, including the culture supernatant, periplasm, 
cytoplasm, cytoplasmic membrane, and outer membrane, from both M93Sm and S262 (Figure 5A). However, when the assay was performed at $64^{\circ} \mathrm{C}$ (to inactivate heat labile phospholipases), phospholipase A2 activity in S262 was significantly decreased in all fractions including the supernatant (Figure 5B). Additionally, when the assay was performed at $64^{\circ} \mathrm{C}$ for M93Sm subcellular fractions, only the culture supernatant exhibited phospholipase activity against BPC (about 100-fold higher activity compared to the phospholipase activity of the S262 supernatant). The data demonstrated that Plp was secreted into the culture supernatant of $V$. anguillarum, which corresponds with in silico analysis of the deduced Plp amino acid sequence (Accession number DQ008059) by SignalP that Plp has a signal peptide [18]. TLC results also revealed that there was at least one other protein in $V$. anguillarum M93Sm exhibiting phospholipase A2 activity besides the secreted, heat stable Plp protein. This was a themolabile PLA2 activity inactivated at $64^{\circ} \mathrm{C}$.

In order to confirm that Plp was localized in the supernatant of $V$. anguillarum, protein samples prepared from various subcellular fractions were separated by SDS-PAGE and analyzed by western blot analysis using polyclonal rabbit anti-Plp antiserum. An immunoreactive band of $\sim 45 \mathrm{kDa}$ was detected only in the supernatant of M93Sm, but was absent in the supernatant of $p l p$ mutant (Figure 5C). Taken together with the phospholipase A2 activity data, these data indicate that Plp is a secreted protein in V. anguillarum.

\section{rPlp has a specific activity against phosphatidylcholine}

Various fluorescently-labeled phospholipid substrates (described in Methods) were used to determine the specificity of the rPlp protein. rPlp exhibited high activity against phosphatidylcholine, cleaving BPC to yield BLPC and free fatty acid (Figures 3 and 6A). However, rPlp had almost no activity against both NBD-phosphatidylethanolamine (NBD-PE) (Figure 6B) and NBD-phosphatidylserine (NBDPS) (Figure $6 \mathrm{C}$ ), showing only $2 \%$ and $5 \%$, respectively, of the activity of the standard PLA2 protein against each of the substrates. The data indicated that the rPlp protein does not efficiently cleave either phosphatidylethanolamine or phosphatidylserine. Additionally, unlike the standard sphingomyelinase, rPlp was not able to cleave the NBD-sphingomyelin into the NBD-ceramide and phosphocholine (Figure 6D), indicating that rPlp had no sphingomyelinase activity. Taken together, the data demonstrated that Plp is a phosphatidylcholine-specific PLA2 enzyme.

\section{rPlp is able to lyse the fish erythrocytes directly}

Membrane phospholipid compositions are quite varied among the animal species, especially for phosphatidylcholine. It is known that phosphatidylcholine makes up $58 \%$ of the total phospholipid in fish erythrocytes [19];

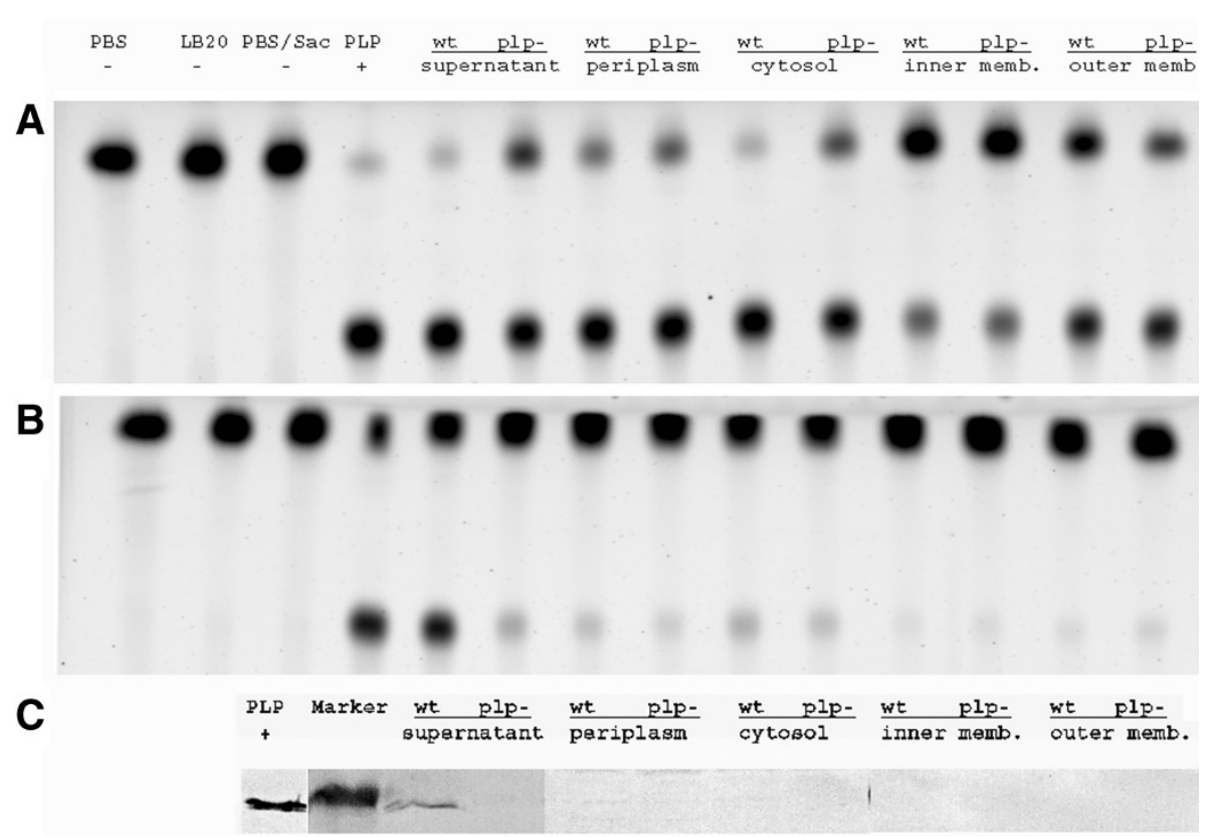

Figure 5 The phospholipase activity assays detected by TLC of various cell fractions prepared from wild type (wt) strain M93sm and plp mutant strain S262 (plp-) were performed at $37^{\circ} \mathrm{C}(\mathrm{A})$ and $64^{\circ} \mathrm{C}$ (B). PBS buffer, LB20, and PBS buffer $+1 \%$ sarcosylate were served as negative controls. The refolded rPlp protein (PLP +) served as positive control. The top spots on each chromatogram are the BPC substrate and the bottom spots are the BLPC reaction product. The proteins from the same cell fractionation preparations were analyzed by SDS-PAGE and Western blot analysis $\mathbf{( C )}$ as described in the Methods. The refolded rPlp protein was served as positive control. 


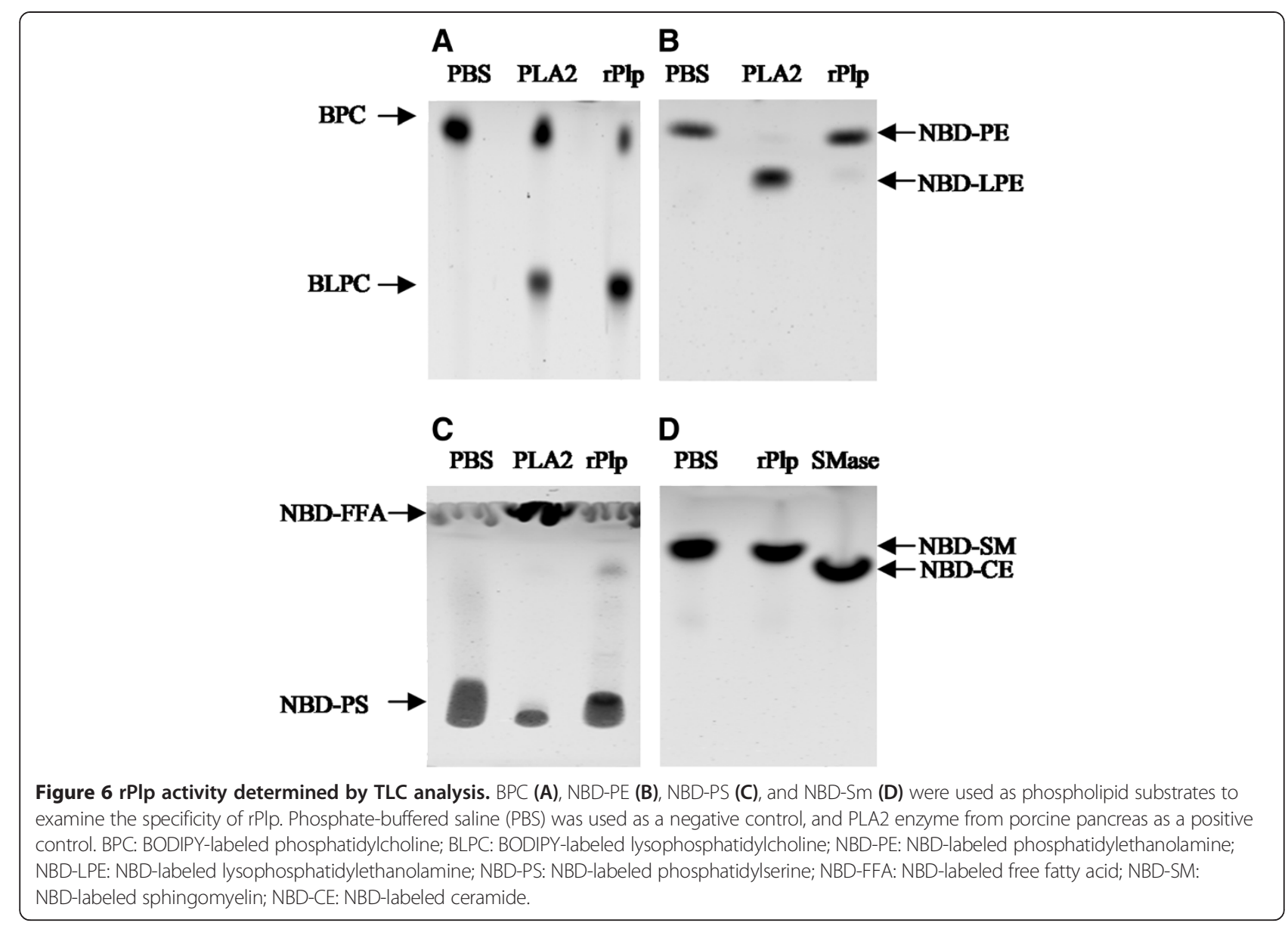

however, no phosphatidylcholine is found in sheep erythrocytes [20]. In order to determine whether the differential hemolysis observed for plp mutants of $V$. anguillarum (Figure 2) is due to the activity of Plp against $\mathrm{PC}$, we tested the ability of purified rPlp to lyse Atlantic salmon erythrocytes. Addition of recombinant Plp resulted in the lysis of Atlantic salmon erythrocytes, with the amount of lysis directly related to the amount of rPlp added to the blood suspension (Figure 7). In contrast, addition of rPlp to a suspension of sheep erythrocytes resulted in no lysis of those cells (Figure 7). These data show that Plp has phosphatidylcholine-specific phospholipase A2 activity and can directly lyse fish erythrocytes.

\section{PIp is one of the hemolysins of $V$. anguillarum}

Previously, we demonstrated that there are two major hemolysin gene clusters in the M93Sm, the vah1 cluster [8] and the $r t x A$ cluster [9]. Mutation of both vah1 and $r t x A$ completely eliminated the hemolytic activity of M93Sm on TSA-sheep blood agar [9]. Mutation of the plp gene resulted in 2-3-fold increased hemolytic activity on TSA-sheep blood agar because vah1 expression increased both transcriptionally and translationally in the

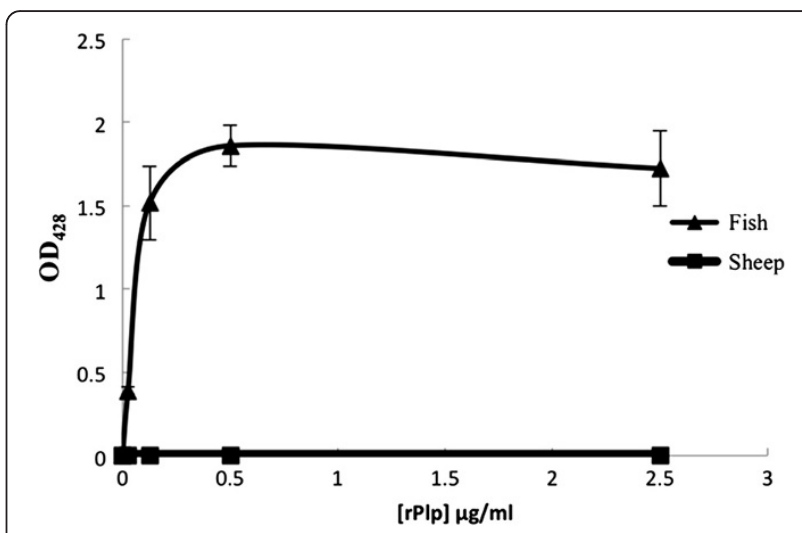

Figure $\mathbf{7}$ Lysis of Atlantic salmon erythrocytes by recombinant Plp protein (rPlp). $500 \mu \mathrm{l} \%$ fish (triangle) and sheep (square) erythrocytes were incubated with various concentration rPlp at $27^{\circ} \mathrm{C}$ for $20 \mathrm{~h}$. The lysis of erythrocytes was measured at $428 \mathrm{~nm}$. Erythrocyte resuspension buffer (10 mM Tris- $\mathrm{HCl}, 0.9 \% \mathrm{NaCl}, \mathrm{pH}$ 7.2) was used as negative control. All values were calculated from three independent experiments. Error bars show one standard deviation. 
plp mutant, indicating that Plp is a putative repressor of vah1 [9]. Plp also has hemolytic activity against fish erythrocytes due to its phosphatidylcholine-specific activity (Figures 6 and 7). To investigate the relationship of the three hemolysins, culture supernatants obtained from various $V$. anguillarum strains (Table 1) were used to examine the hemolytic activity against the fish blood (Table 2).

In contrast to the strong hemolytic activity against 5\% rainbow trout blood mixed with culture supernatant from the wild type strain M93Sm, hemolytic activity of culture supernatant from strain S262 ( $p l p)$ declined by $>70 \%$ (Table 2). Additionally, all mutants containing a knockout of $p l p$ exhibited significant declines $(P<0.05)$ in hemolytic activity. The triple hemolysin mutant, XM90 (plp vah1 $r t x A$ ) had no ability to lyse fish erythrocytes (Table 2). However, mutations in either vah1 or $r t x A$, but not $p l p$, resulted in little or no decline in hemolytic activity against fish erythrocytes compared to supernatants from wild type cells (Table 2). Further, complementation of $p l p$ restored the hemolytic activity of supernatants from both the plp-complemented strains (XM31, plp + and XM93, vah1 rtxA plp+) (Table 2). Taken together, these data clearly demonstrate that Plp is the major hemolytic enzyme responsible for the lysis of rainbow trout erythrocytes by culture supernatants of $V$. anguillarum.

\section{Plp is not a major virulence factor for $V$. anguillarum during fish infection}

In order to determine whether the $p l p$ gene affects virulence in fish, an infection study was performed by inoculating rainbow trout by IP injection with either the wild type strain M93Sm or mutant strains S262 (plp) or JR03 (vah1 plp). The results of this experiment (Figure 8) indicated that there were no statistical differences in mortality between the three strains. This suggested that mutation of either plp or vah1 or both genes did not decrease the virulence of $\mathrm{M} 93 \mathrm{Sm}$. These results are consistent with our previous observations that $r t x A$ is a major virulence factor of M93sm and that mutation of vah1 does not affect virulence [8], and demonstrate that $\mathrm{Plp}$ is not a major virulence factor in the $V$. anguillarum M93Sm.

\section{Discussion}

In this report, we describe the characteristics of the $V$. anguillarum phospholipase protein (Plp) encoded by $p l p$, and its contribution to the hemolytic activity of $V$. anguillarum. Specifically, we show that Plp is a secreted phospholipase with A2 activity with specificity for phosphatidylcholine. The enzyme has a broad temperature optimum $\left(37-64^{\circ} \mathrm{C}\right)$ and a broad $\mathrm{pH}$ optimum $(\mathrm{pH} 5.5-$ 8.7). Phospholipases are broadly distributed among the
Vibrionaceae and often contribute to the virulence of the pathogenic members of this family. For example, the TLH or LDH of $V$. parahaemolyticus [23-25] was the first wellstudied lecithin-dependent PLA/lysophospholipase [26]. A lecithinase (encoded by lec) was also identified in $V$. cholerae [27]. Fiore et al. [27] found that a lec mutant strain was unable to degrade lecithin and the culture supernatant exhibited decreased cytotoxicity. However, the mutant did not exhibit decreased fluid accumulation in a rabbit ileal loop assay, suggesting that fluid accumulation in animals is not affected by lecithinase activity. Additionally, the phospholipase A (PhlA) in V. mimicus was found to exhibit hemolytic activity against trout and tilapia erythrocytes and was cytotoxic to the fish cell line CHSE-214 [28]. Recently, the $V$. harveyi hemolysin (VHH) was shown to be a virulence factor during flounder infection and also had phospholipase activity on egg yolk agar [29]. Rock and Nelson [8] reported that the putative phospholipase gene ( $p l p$ ) from $V$. anguillarum exhibits 69\% amino acid identity with the $V$. cholerae lec gene. Both $p l p$ and lec are located divergently adjacent to a hemolysin gene (vah1 and hlyA, respectively) [8,27]. Additionally, Rock and Nelson [8] demonstrated that functional plp repressed transcription of its adjacent hemolysin gene, vah1, in $V$. anguillarum. However, the enzymatic characteristics of Plp in V. anguillarum were not described.

Usually, phospholipases are divided into phospholipases A (A1 and A2), C, and D according to the cleavage position on target phospholipids. Most of lipolytic enzymes contain a putative lipid catalytic motif (GDSL) that was previously demonstrated in other bacterial and eukaryotic phospholipases [30]. However, Molgaard [16] demonstrated that four amino acid residues (SGNH) form a catalytic site, and are conserved in all members of the phospholipase family; therefore, phospholipases were re-named as the SGNH subgroup of the GDSL family [30]. Multiple alignment analysis of 17 phospholipase homologues (Figure 1) demonstrates that $V$. anguillarum Plp belongs to the SGNH hydrolase subgroup, since the GSDL motif was not fully conserved in these proteins (Figure 1). Recently, it was reported that mutation of the serine residue in the SGNH motif resulted in the complete loss of the phospholipase and hemolytic activities of $\mathrm{VHH}$ in $V$. harveyi [31] demonstrating the importance of this motif on the activity of phospholipase.

In contrast to the similarities of their catalytic motifs, the biochemical characteristics of bacterial phospholipases appear to be variable. For example, $V$. mimicus PhlA has a phospholipase A activity, which cleaves the fatty acid at either sn-1or sn-2 position, but no lysophospholipase activity [28]. Two phospholipases identified from mesophilic Aeromonas sp. serogroup O:34 show phospholipase A1 and C activity [32]. In addition, TLH of $V$. parahaemolyticus has PLA2 and lysophospholipase 
Table 1 Bacterial strains and plasmids used in this study

\begin{tabular}{|c|c|c|}
\hline Strain or plasmid & Description & Reference \\
\hline \multicolumn{3}{|l|}{ V. anguillarum strains } \\
\hline M93sm & $\begin{array}{l}\text { Spontaneous } \mathrm{Sm} \mathrm{m}^{r} \text { mutant of M93 (serotype O2a); parental strain isolated } \\
\text { from a diseased ayu (Plecoglossus altivelis) from Lake Biwa, Japan }\end{array}$ & {$[2]$} \\
\hline JR1 & $\mathrm{Sm}^{r} \mathrm{Cm}^{r}$ vah1; insertional vah1 mutant of $\mathrm{M} 93 \mathrm{Sm}$ & [8] \\
\hline XM21 & $\mathrm{Sm}^{r} \mathrm{Cm}^{r} \mathrm{TC}{ }^{r}$ vah1+; vah1 complement strain of JR1 & This study \\
\hline S262 & $\mathrm{Sm}^{r} \mathrm{Cm}^{r} p / p$; insertional plp mutant of M93Sm & This study \\
\hline XM31 & $\mathrm{Sm}^{r} \mathrm{Cm}^{r} \mathrm{~T} c^{r} p / p+;$ plp complement strain of $\mathrm{S} 262$ & This study \\
\hline S123 & $\mathrm{Sm}^{r} \mathrm{Cm}^{r} r t x A$; insertional rtxA mutant of $\mathrm{M} 93 \mathrm{Sm}$ & [9] \\
\hline JR3 & $\mathrm{Sm}^{r} \mathrm{Cm}^{r} \mathrm{Km}^{r}$ vah1 plp; insertional vah1mutant of JL01 & [8] \\
\hline S183 & $\mathrm{Sm}^{r} \mathrm{Cm}^{r} \mathrm{Km}^{r}$ vah1 rtxA; insertional rtxA mutant of S171 & [9] \\
\hline XM62 & $\mathrm{Sm}^{r} \mathrm{Cm}^{r} \mathrm{Km}^{r} \mathrm{Tc}^{r}$ vah1+rtxA; vah1 complement strain of $\mathrm{S} 183$ & This study \\
\hline S187 & $\mathrm{Sm}^{r} \mathrm{Cm}^{r} \mathrm{Km}^{r}$ plp rtxA; insertional rtxA mutant of JL01 & This study \\
\hline XM90 & $\mathrm{Sm}^{r} \mathrm{Cm}^{r} \mathrm{Km}^{r}$ vah1 plp rtxA; insertional plp mutant of S264 & This study \\
\hline XM93 & $\mathrm{Sm}^{r} \mathrm{Cm}^{r} \mathrm{Km}^{r} \mathrm{~T} c^{r}$ vah1 plp +rtxA; plp complement strain of XM90 & This study \\
\hline JL01 & $\mathrm{Sm}^{r} \mathrm{Km}^{r} p / p ;$ mini-Tn10Km insertion into plp & [8] \\
\hline S171 & $\mathrm{Sm}^{r} \mathrm{Km}^{r}$ vah1; allelic exchange vah1 mutant & [9] \\
\hline S264 & $\mathrm{Sm}^{r} \mathrm{Km}^{r}$ vah1 rtxA; allelic exchange vah1 and $r$ txA mutant & This study \\
\hline \multicolumn{3}{|l|}{ E. coli strains } \\
\hline Sm10 & thi thr leu tonA lacY supE recA RP4-2-Tc::Mu::Km ( $\lambda$ pir) & [21] \\
\hline S253 & $\mathrm{Km}^{r} \mathrm{Cm}^{\mathrm{r}}$; Sm10 containing plasmid pNQ705-plp & This study \\
\hline S118 & $\mathrm{Km}^{\mathrm{r}} \mathrm{Cm}^{\mathrm{r}} ; \mathrm{Sm} 10$ containing plasmid pNQ705-rtxA & [9] \\
\hline S250 & $\mathrm{Km}^{\mathrm{r}} \mathrm{Cm}^{\mathrm{r}} ; \mathrm{Sm} 10$ containing plasmid pDM4-rtxA5' & This study \\
\hline S252 & $\mathrm{Km}^{r} \mathrm{Cm}^{r} ;$ Sm10 containing plasmid pDM4-rtxA5'-rtxA3' & This study \\
\hline U21 & $\mathrm{Km}^{r} \mathrm{Ap}{ }^{r} \mathrm{TC}^{r} ;$ Sm10 containing plasmid pSUP202-vah1 & This study \\
\hline U31 & $\mathrm{Km}^{r} \mathrm{Ap} \mathrm{p}^{\mathrm{r}} \mathrm{Tc}^{\mathrm{r}} ; \mathrm{Sm} 10$ containing plasmid pSUP202-plp & This study \\
\hline M15 & $\mathrm{Nal}^{\mathrm{S}} \mathrm{Str}^{\mathrm{S}} \mathrm{Rif}^{\mathrm{S}}$ thi lac $^{-} \mathrm{ara}^{+} \mathrm{gal}^{+} \mathrm{mtl}^{-} \mathrm{F}^{-}$recA $A^{+} \mathrm{uvr}^{+}$lon $^{+}$(pREP4) & QIAGEN, USA \\
\hline S238 & $\mathrm{Km}^{\mathrm{r}} \mathrm{Ap}$; $;$ M15 containing plasmid pQE30UA-plp & This study \\
\hline S269 & $\mathrm{Km}^{r} \mathrm{Ap}{ }^{\mathrm{r}} ; \mathrm{M} 15$ containing plasmid pQE60-plp & This study \\
\hline \multicolumn{3}{|l|}{ Plasmid } \\
\hline PCR2.1 & $\mathrm{Km}^{\mathrm{r}} \mathrm{Ap}{ }^{\mathrm{r}}$; Cloning vector & Invitrogen, USA \\
\hline pNQ705-1 & $\mathrm{Cm}^{r}$; suicide vector with R6K origin & [22] \\
\hline pNQ705-vah1 & $\mathrm{Cm}^{\mathrm{r}}$; for insertional vah1mutation & {$[8]$} \\
\hline pNQ705-p/p & $\mathrm{Cm}^{r}$; for insertional plp mutation & This study \\
\hline pNQ705-rtxA & $\mathrm{Cm}^{\mathrm{r}}$; for insertional rtxA mutation & [9] \\
\hline pDM4 & $\mathrm{Cm}^{r} \mathrm{SacBC}$; suicide vector with R6K origin & [11] \\
\hline pDM4-rtxA5'-rtxA3' & $\mathrm{Cm}^{r} \mathrm{SacBC}$; for allelic exchange $r t x A$ mutation & This study \\
\hline pSUP202 & $\mathrm{Cm}^{r} \mathrm{Ap}^{r} \mathrm{Tc}^{r} ;$ E. coli - V. anguillarum shuttle vector & [21] \\
\hline pSUP202-vah1 & $A p^{r} T c^{r}$; for complementation of vah1 & This study \\
\hline pSUP202-plp & $A p^{r} T c^{r}$; for complementation of $p / p$ & This study \\
\hline PQE-30 UA & $A p^{r}$; expression vector with $\mathrm{N}$-terminal $\mathrm{His}_{6}$-tag & QIAGEN, USA \\
\hline pQE30UA-plp & $A p^{r}$; for expression of rPlp that is used to make anti-Plp & This study \\
\hline pQE60 & $A p^{r}$; expression vector with C-terminal $\mathrm{His}_{6}$-tag & QIAGEN, USA \\
\hline pQE-60-p/p & $A p^{r}$; for expression of rPlp for enzymatic activity analysis & This study \\
\hline
\end{tabular}


Table 2 Hemolytic activity of culture supernatant from $V$. anguillarum wild-type and various $V$. anguillarum mutant strains against rainbow trout blood cells

\begin{tabular}{|c|c|}
\hline V. anguillarum strain or treatment & 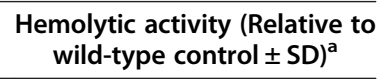 \\
\hline M93Sm & $1.00( \pm 0.12)$ \\
\hline JR1 (vah1) & $0.98( \pm 0.16)$ \\
\hline XM21 (vah1+) & $1.20( \pm 0.28)$ \\
\hline $\mathrm{S} 262(p / p)$ & $0.28( \pm 0.09)^{\mathrm{b}}$ \\
\hline XM31 (p/p+) & $0.99( \pm 0.04)$ \\
\hline $\mathrm{S} 123(r t \times A)$ & $0.94( \pm 0.22)$ \\
\hline JR03 (plp vah1) & $0.14( \pm 0.09)^{\mathrm{b}}$ \\
\hline S183 (vah1 rtxA) & $1.51( \pm 0.29)$ \\
\hline XM62 (vah1+rtxA) & $0.73( \pm 0.03)$ \\
\hline $\mathrm{S} 187$ (plp rtxA) & $0.12( \pm 0.09)^{b}$ \\
\hline XM90 (vah1 rtxA plp) & $-0.04( \pm 0.09)^{b}$ \\
\hline XM93 (vah1 rtxA plp+) & $1.33( \pm 0.01)$ \\
\hline Water (positive control) & $1.15( \pm 0.16)$ \\
\hline
\end{tabular}

${ }^{a}$ Hemolytic activity assays carried out using the tube assay method as described in the Methods. Hemolysis by M93Sm was given the value of 1.00 . The data are representative of two independent experiments, each with three replicates, \pm one standard deviation (SD).

${ }^{\mathrm{b}}$ Statistically different from hemolytic activity for M93Sm $(P<0.05)$.

activity, and demonstrates a loss of activity at $55^{\circ} \mathrm{C}$ for $10 \mathrm{~min}$ [23]. In this report, we show that $V$. anguillarum Plp has PLA2 activity, and is able to maintain activity at $64^{\circ} \mathrm{C}$ for $1 \mathrm{~h}$ (Figures 6 and 7). Therefore, the enzymatic characteristics of specific phospholipases are distinct even when they all belong to the SGNH hydrolase family (Figure 1).

Phospholipases have been implicated in the pathogenic activities of a number of bacteria [33,34]. It is known that phospholipase activities often lead to cell destruction by degrading the phospholipids of cell membranes $[33,35]$. However, the relationships between phospholipases and virulence are not always clear. While the purified rPlp exhibits strong hemolytic activity against Atlantic salmon erythrocytes (Figure 7), Rock and Nelson [8] showed that a knock-out mutation of either the plp gene or the vah1 gene in $V$. anguillarum did not affect virulence of $V$. anguillarum during an infection study on juvenile Atlantic salmon. In this report, we show that when groups of rainbow trout are infected with either a plp mutant or a plp vah1 double mutant there is no significant difference in mortalities compared to fish infected with the wild type strain. Our data suggest that neither $p l p$ nor vah1 are major virulence factors during pathogenesis of salmonids. It was also reported that the deletion of lecithinase (Lec) activity in $V$. cholerae did not significantly diminish fluid accumulation in the rabbit ileal loop assay, indicating the lecithinase activity does not contribute significantly to enterotoxin activity [27]. Lec is a homologue
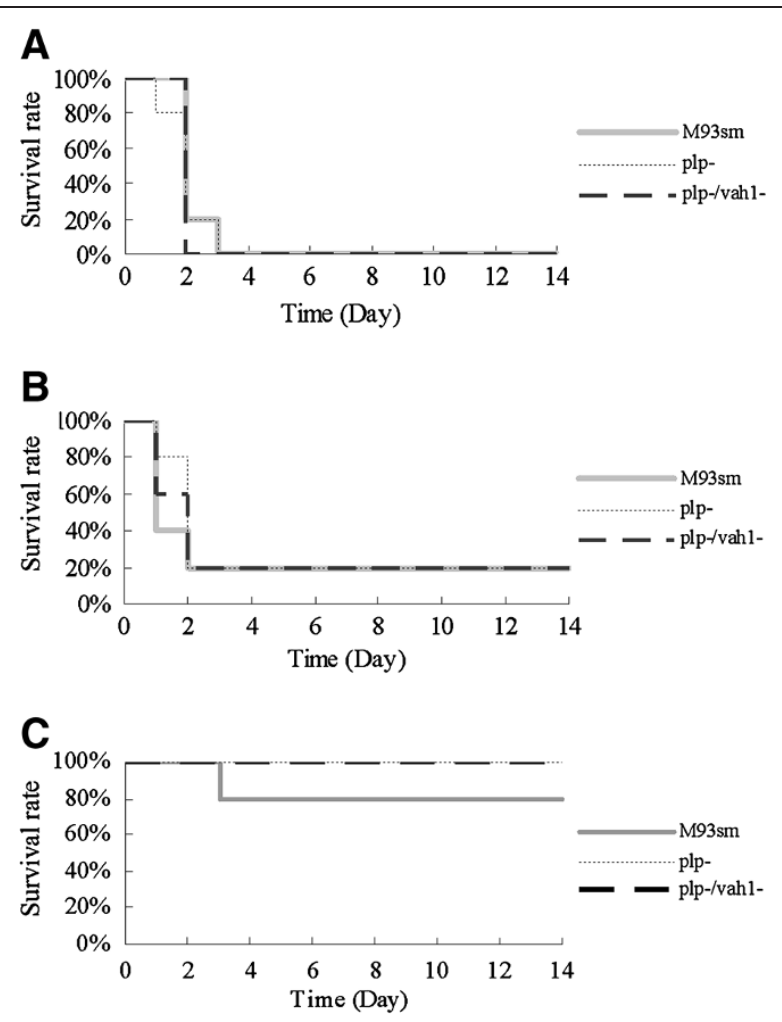

Figure 8 Survival rate of rainbow trout injected IP with wild type (M93Sm, solid grey line) and mutant (p/p, grey dotted line; plp vah1, black dashed line) strains of $V$. anguillarum strains at doses of A) $3 \times 10^{6}$, B) $3 \times 10^{5}$ or C) $3 \times 10^{4} \mathrm{CFU} /$ fish. No statistically significant difference was observed between the strains.

of Plp [8]. In contrast, the direct IP injection of purified $V$. harveyi $\mathrm{VHH}$ protein caused the death of flounder with an $\mathrm{LD}_{50}$ of about 18.4 $\mu \mathrm{g}$ protein/fish [29]. The rPhlA of $V$. mimicus also has a direct cytotoxic effect on the fish cell line CHSE-214 [28] suggesting that this phospholipase is a virulence factor during fish infection. In addition, the lecithinase purified from $A$. hydrophila (serogroup O:34) has been shown to be an important virulence factor to rainbow trout and mouse [32]. We note that infection experiments in both Atlantic salmon and rainbow trout demonstrate that mutation of $p l p$ does not attenuate virulence. We propose that $V$. anguillarum is able to compensate for the loss of Plp-mediated hemolytic activity in vivo by up-regulating the transcription of vah1, as previously described by Rock and Nelson [8]. Additionally, transcription of $r t x A$ is also increased in a plp mutant (Mou and Nelson, unpublished data).

Generally, the hemolytic activity of phospholipases is dependent upon the hydrolysis of the phospholipids that reside in the erythrocyte membrane. Erythrocytes contain various phospholipids including phosphatidylcholine (PC), phosphatidylethanolamine (PE), phosphatidylserine (PS), phosphatidylinositol (PI), and sphingomyelin (SM). PC 
makes up 58\% of the total erythrocyte phospholipids in the Atlantic salmon [36], but only $34 \%$ and $1 \%$ in rabbit and sheep erythrocytes, respectively [20]. Taken together with the high specificity of rPlp for PC (Figure 6), it was not surprising that rPlp was able to lyse the fish erythrocytes, but not sheep erythrocytes (Figure 7), and that the plp mutant had decreased hemolytic activity on LB20-fish blood agar (Figure 2). Our results are consistent were those reported for $V$. mimicus PhlA [28] and $V$. harveyi $\mathrm{VHH}$ [29], in which PhlA and VVH specifically lyse the fish erythrocytes.

We have previously reported that there are two hemolysin gene clusters in $V$. anguillarum M93Sm, the vah1-plp cluster and $r t x A C H B D E$ cluster [9] and have described their regulation by $\mathrm{H}-\mathrm{NS}$ and HlyU $[17,37]$. Mutation of both vah1 and $r t x A$ results in the loss of all hemolytic activity on TSA-sheep blood agar [9], which is consistent with the data reported here that Plp has no activity on sheep erythrocytes. We have also previously demonstrated that Plp is a putative repressor of Vah1, since mutation of $p l p$ increases vah1 expression by 2-3 fold [8]. In this report, we examined the hemolytic activity of various hemolysin mutants using freshly collected Rainbow trout blood (Table 2) to investigate the relationships among three hemolysins of $V$. anguillarum. While culture supernatants from two of the three single mutants (JR1 and S123) and one of three double mutants (S183) exhibited $\geq 94 \%$ of the hemolytic activity as supernatants from the wild type strain M93Sm (Table 2), the hemolytic activity of one single mutant (S262, plp) and two double mutants (JR03, plp vah1 and S187, plp rtxA) were reduced to $28 \%, 14 \%$, and $12 \%$ of that in M93Sm, respectively. Our data indicate that only the loss of the plp gene has a significant effect on hemolysis of fish erythrocytes by $V$. anguillarum culture supernatant, while the loss of $r t x A$ and/or vah1 has little effect. Further, supernatant from the hemolysin triple mutant XM90 (vah1 rtxA plp) exhibits no hemolytic activity on fish blood compared to M93Sm (Table 2), indicating that Vah1, RtxA, and Plp are responsible for all secreted hemolytic activity by $V$. anguillarum. Finally, complementation of any plp mutant with plp (in trans) restores hemolytic activity to $V$. anguillarum culture supernatant (Table 2).

\section{Conclusion}

$V$. anguillarum $\mathrm{Plp}$ is a secreted hemolysin with phosphatidylcholine-specific phospholipase A2 activity. The ability of Plp to digest the abundant phosphatidylcholine found in the membrane of fish erythrocytes causes their lysis. The three hemolysins, Plp, Vah1 and RtxA, account for all hemolytic activity in $V$. anguillarum culture supernatant under the experiment conditions described in this study. Finally, infection studies in rainbow trout demonstrate that the $p l p$ and vah1 genes are not required for virulence.

\section{Methods}

\section{Bacterial strains, plasmids, and growth conditions}

All bacterial strains and plasmids used in this report are listed in Table 1. V. anguillarum strains were routinely grown in Luria-Bertani broth plus $2 \% \mathrm{NaCl}$ (LB20) [38], supplemented with the appropriate antibiotic, in a shaking water bath at $27^{\circ} \mathrm{C}$. E. coli strains were routinely grown in Luria-Bertani broth plus $1 \% \mathrm{NaCl}$ (LB10). Antibiotics were used at the following concentrations:

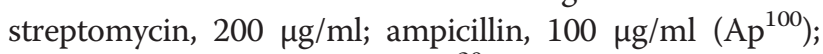
chloramphenicol, $20 \mu \mathrm{g} / \mathrm{ml}\left(\mathrm{Cm}^{20}\right)$ for $E$. coli and $5 \mu \mathrm{g} / \mathrm{ml}$ $\left(\mathrm{Cm}^{5}\right)$ for $V$. anguillarum; kanamycin, $50 \mu \mathrm{g} / \mathrm{ml}\left(\mathrm{Km}^{50}\right)$ for E. coli and $80 \mu \mathrm{g} / \mathrm{ml}\left(\mathrm{Km}^{80}\right)$ for $V$. anguillarum; tetracycline, $15 \mu \mathrm{g} / \mathrm{ml}\left(\mathrm{Tc}^{15}\right)$ for E. coli, $1 \mu \mathrm{g} / \mathrm{ml}\left(\mathrm{Tc}^{1}\right)$ for $V$. anguillarum grown in liquid medium, and $2 \mu \mathrm{g} / \mathrm{ml}\left(\mathrm{Tc}^{2}\right)$ for $V$. anguillarum grown on agar plates.

\section{Insertional mutagenesis}

Insertional mutations were made by using a modification of the procedure described by Milton et al. [28]. Briefly, primers (Table 3) were designed based on the target gene sequence of M93Sm. Then a 200-300 bp DNA fragment of the target gene was PCR amplified and ligated into the suicide vector pNQ705-1 (GenBank accession no. KC795685) after digestion with $S a c I$ and $X b a \mathrm{I}$. The ligation mixture was introduced into $E$. coli Sm10 by electroporation using BioRad Gene Pulser II (BioRad, Hercules, CA). Transformants were selected on LB10 $\mathrm{Cm}^{20}$ agar plates. The construction of the recombinant pNQ705 was confirmed by both PCR amplification and restriction analysis. The mobilizable suicide vector was transferred from $E$. coli Sm10 into $V$. anguillarum by conjugation. Transconjugants were selected by utilizing the chloramphenicol resistance gene located on the suicide plasmid. The incorporation of the recombinant pNQ705 was confirmed by PCR amplification.

\section{Allelic exchange mutagenesis}

The allelic exchange $r t x A$ mutation in $V$. anguillarum S264 was made by using a modification of the procedure described by Milton et al. [28]. The 5' region of $r t x A$ was amplified using the primer pair pm256 and pm257 (Table 3), digested with XhoI and XbaI, and then cloned into the region between the $\mathrm{XhoI}$ and $\mathrm{XbaI}$ sites on pDM4 (GenBank accession no. KC795686), deriving pDM4-rtx $A 5^{\prime}$. The $3^{\prime}$ region of $r t x A$ was amplified using the primer pair pm258 and pm259 (Table 3), digested with $\mathrm{XbaI}$ and SacI, and then cloned into the region between the $\mathrm{XbaI}$ and SacI sites on the pDM4-rtxA5'. The resulting pDM4-rtx $A 5^{\prime}-r t x A 3^{\prime}$ was transformed into E. coli Sm10 to produce the transformant strain S252, which was mated with $V$. anguillarum S171 (vah1). Single-crossover transconjugants were selected with LB20 $\mathrm{Kan}^{80} \mathrm{Sm}^{200} \mathrm{Cm}^{5}$ plates and, subsequently, double-crossover transconjugants 
Table 3 Primers used in this study

\begin{tabular}{|c|c|c|c|}
\hline Primers & $\begin{array}{l}\text { Sequence (5' to } 3 \text { ', italicized sequences } \\
\text { are designed restriction sites) }\end{array}$ & Purpose and description & Reference \\
\hline Pm262 & ATCGAGGATCCATGAAACTAATGACGTTATTG & For whole Plp protein, forward & This study \\
\hline Pm263 & ATCGAAGATCTTTGAAATTGAAATGACGCGAG & For whole Plp protein, reverse & This study \\
\hline Pm212 & GACACCTCACAATATGAAATAAAA & For truncated Plp protein, forward & This study \\
\hline Pm213 & TTTGAGCTGCGGGGCTTTGGTTGC & For truncated Plp protein, reverse & This study \\
\hline Pm261 & ATCGAGAGCTCGCAGAATCGTGACTGACGCCG & For insertional plp mutation, forward, with Sacl site & This study \\
\hline SD Lip/Heme R1 & GCTAGTCTAGAACGGATACCACCTCAGA & For insertional plp mutation, reverse, with Xbal site & [8] \\
\hline pr1 & GGGGAATTCTAATTCAAATTGAAATGACGCGAG & For plp complement, forward, with EcoRl site & This study \\
\hline pr2 & GGGACCGGTGAATACCCATTITITATIITTC & For plp complement, reverse, with Agel site & This study \\
\hline pr3 & GTTGAATTCGTATTTTCTGCAATCGCCATG & For vah1 complement, forward, with EcoRl site & This study \\
\hline pr4 & GGGACCGGTCTATTITATAATAAATTGAATACCAT & For vah1 complement, reverse, with Agel site & This study \\
\hline Pm256 & ATCGACTCGAGCTGGAGAAGATGTACTCTGCG & For allelic exchange rtxA mutation, flanking the 5 ' region, forward, with Xhol site & This study \\
\hline Pm257 & ATCGATCTAGACGTATCATCTACAGCTITTGC & For allelic exchange rtxA mutation, flanking the 5 ' region, reverse, with Xbal site & This study \\
\hline Pm258 & ATCGATCTAGATTATATTAATCATGTCTITTATGGG & For allelic exchange rtxA mutation, flanking the $3^{\prime}$ region, forward, with Xbal site & This study \\
\hline Pm259 & ATCGAGAGCTCCTGATTGCCTAGCAGTAGCCC & For allelic exchange rtxA mutation, flanking the 3 ' region, reverse, with Sacl site & This study \\
\hline pr7 & CAGGAAACAGCTATGACCATGATTACG & For sequencing of the DNA fragment inserted in pCR2.1 TA-ligation site & This study \\
\hline pr8 & CTACGGGCTTGAGCGTGACAATC & For sequencing of the DNA fragment inserted in pSUP202 Agel site & This study \\
\hline pr25ex & GCTGTCCCTCCTGTTCAGCTACTGACGGGGTGGTGCG & For sequencing of the DNA fragment inserted in pNQ705-1 Multi-cloning site & This study \\
\hline
\end{tabular}

(resulting in a 3345 bp deletion in C-terminal of RtxA) were selected with LB20 $\mathrm{Kan}^{80} \mathrm{Sm}^{200} 5 \%$ sucrose plates. The resulting $V$. anguillarum colonies were transferred to TSA-sheep blood agar (Northeast Laboratories Service, Waterville, ME) and screened for none-hemolytic colonies (vah1 $r t x A)$. The resulting colonies were checked for the desired allelic exchange using PCR amplification.

\section{Complementation of mutants}

The various mutants were complemented by cloning the appropriate target gene fragment into the shuttle vector pSUP202 (GenBank accession no. AY428809) as described previously by [8]. Briefly, primers (Table 3) were designed with EcoRI and AgeI sites and then used to amplify the entire target gene plus $\sim 500$ bp of the $5^{\prime}$ and 200 bp 3'flanking regions from genomic DNA of $V$. anguillarum M93Sm. The DNA fragment was then ligated into pSUP202 after digestion with EcoRI and AgeI, and the ligation mixture was introduced into $E$. coli Sm10 by electroporation using a BioRad Gene Pulser II. Transformants were selected on LB10 $\mathrm{Tc}^{15} \mathrm{Ap}^{100}$ agar plates. The complementing plasmid was transferred from E. coli $\mathrm{Sm} 10$ into the $V$. anguillarum mutant by conjugation. Transconjugants were selected by tetracycline resistance $\left(\mathrm{Tc}^{2}\right)$. The transconjugants were then confirmed by PCR amplification and restriction digestion.

\section{Bacterial conjugation}

Bacterial conjugation were carried out using the procedure modified from Varina et al. [39]. Briefly, $100 \mu \mathrm{l}$. anguillarum grown overnight was added into $2.5 \mathrm{ml}$ nine salts solution (NSS) [40]; $100 \mu \mathrm{l}$ E. coli culture overnight was added into $2.5 \mathrm{ml} 10 \mathrm{mM} \mathrm{MgSO}_{4}$. The resulting $V$. anguillarum and $E$. coli suspension was mixed, vacuum filtered onto an autoclaved $0.22-\mu \mathrm{m}$-pore-diameter nylon membrane (Millipore, USA), placed on an LB15 agar plate (LB-plus-1.5\% $\mathrm{NaCl}$ ), and allowed to incubate overnight at $27^{\circ} \mathrm{C}$. Following incubation, the cells were removed from the filter by vigorous vortex mixing in $1 \mathrm{ml} \mathrm{NSS}$. Cell suspensions $(70 \mu \mathrm{l})$ were spread on LB20 plated with appropriate antibiotics and the plates were incubated at $27^{\circ} \mathrm{C}$ until $V$. anguillarum colonies were observed (usually 24 to $48 \mathrm{~h}$ ).

\section{Cloning, over-expression, purification, and refolding of the Plp protein}

The whole length of the plp gene (stop codon not included) was amplified by PCR with a sense primer introducing a BamHI site and an antisense primer introducing BglII site, respectively. Genomic DNA extracted from $V$. anguillarum M93Sm was used as template. The amplified PCR product was digested with BamHI and BglII, and ligated into a pQE60 (QIAGEN, USA) vector, which was also cut with BamHI and BglII. The ligation mix was transformed into E. coli M15 (pREP4) and clones with pQE60-plp were selected on LB10 agar containing kanamycin and ampicillin. A clone harboring plasmid pQE60plp was selected and the plasmid DNA sequence isolated from the clone confirmed by sequencing. The clone was designated as S269. Subsequently, E. coli strain S269 was grown at $37^{\circ} \mathrm{C}$ in $500 \mathrm{ml} \mathrm{LB10}$ broth to $\mathrm{OD}_{600}=0.5$, and isopropyl- $\beta$-D-thiogalactopyranoside (IPTG) was added to 
the culture (final concentration, $1 \mathrm{mM}$ ) to induce the expression of Plp. Then, the induced $E$. coli cells grown for $4 \mathrm{~h}$ at $37^{\circ} \mathrm{C}$ were harvested at $8000 \times g$ for $10 \mathrm{~min}$. The cell pellet was stored at $-20^{\circ} \mathrm{C}$ overnight to improve lysis. Inclusion bodies of Plp were crudely purified using Cellytic $B$ reagent (Sigma, USA). Refolding of Plp protein from the inclusion body preparation was carried out using a modification of the method described by Santa et al. [41]. Briefly, $500 \mu \mathrm{l}$ of purified inclusion body $(2 \mathrm{mg}$ protein $/ \mathrm{ml}$ ) was completely solubilized in $1 \mathrm{ml}$ of $50 \mathrm{mM}$ Tris buffer $(\mathrm{pH} 12)$ containing $2 \mathrm{M}$ urea. The solubilized Plp was diluted into $20 \mathrm{ml}$ dilution buffer $(50 \mathrm{mM}$ Tris- $\mathrm{HCl}$, $\mathrm{pH}$ 8.0; $0.2 \mathrm{M}$ glycine; $10 \%$ glycerol; $2 \mathrm{M}$ urea; $0.5 \mathrm{mM}$ EDTA, and $0.2 \mathrm{mM}$ DTT) at $4^{\circ} \mathrm{C}$. No aggregation was observed during the dilution. The diluted Plp protein was dialyzed with the addition of $500 \mathrm{ml} 50 \mathrm{mM}$ Tris- $\mathrm{HCl}$ (pH8.0) until the total dialysis volume up to $3 \mathrm{~L}$. The dialyzed Plp protein was concentrated with QIAGEN NiNTA Protein Purification Kit (QIAGEN) under native purification condition according to the instructions of the manufacturer. The protein concentration was determined using the BCA protein assay (Pierce).

\section{Hemolytic assays}

The hemolytic activity of $V$. anguillarum strains was measured by two methods. First, single $V$. anguillarum colonies were transferred onto TSA-sheep blood agar, LB20-sheep blood agar (LB20 agar plus 5\% sheep blood with heparin, obtained from Hemostat Laboratories) or LB20-fish blood agar (LB20 agar plus 5\% rainbow trout or Atlantic salmon blood with heparin). Hemolytic activity of each colony was determined by measuring hemolytic zone surrounding the colonies after $24 \mathrm{~h}$ at $27^{\circ} \mathrm{C}$. Additionally, the level of hemolytic activity was also quantitated using a microcentrifuge tube assay. The tubes contained $500 \mu \mathrm{l} 5 \%$ erythrocytes (fish or sheep, suspended in $10 \mathrm{mM}$ Tris- $\mathrm{Cl}$, pH $7.5-0.9 \% \mathrm{NaCl}$ buffer) were mixed with $500 \mu \mathrm{l}$ of bacterial supernatant or rPlp and incubated for $20 \mathrm{~h}$ at $27^{\circ} \mathrm{C}$. The samples were centrifuged at $1500 \times \mathrm{g}$ for $2 \mathrm{~min}$ at $4{ }^{\circ} \mathrm{C}$, and the optical density of the resulting supernatant was read at $428 \mathrm{~nm}$.

\section{Phospholipase assay and thin-layer chromatography (TLC) analysis}

Phospholipase assays were performed in vitro with a BODIPY-phosphatidylcholine (BPC or 2-decanoyl-1-(O(11-(4,4-difluoro-5,7-dimethyl-4-bora-3a,4a-diaza-s-indacene3-propionyl)amino)undecyl)-sn-glycero-3-phosphocholine; Invitrogen), NBD-phosphatidylethanolamine (NBD-PE, $N$-(NBD-Aminododecanoyl)L-1,2-dihexanoyl-sn-glycero3-phosphoethanolamine; Sigma), NBD-phosphatidylserine (NBD-PS or 1-Palmitoyl-2-[12-[(7-nitro-2-1,3-benzoxadiazol4-yl)amino]dodecanoyl]-sn-Glycero-3-Phospho-L-Serine; Avanti Polar Lipid), NBD-sphingomyelin (NBD-SM, N-[12- [(7-nitro-2-1,3-benzoxadiazol-4-yl)amino]dodecanoyl]Sphingosine-1-Phosphocholine; Avanti Polar Lipid). $20 \mu \mathrm{M}$ phospholipid substrates $(10 \mu \mathrm{l})$ were reacted with an equal volume $(10 \mu \mathrm{l})$ of various samples, and incubated at different conditions, as described for each experiment. For some experiments, purified standard phospholipases were used: PLA2 (Sigma) from porcine pancreas, PLC (Sigma) from Clostridium perfringens, and PLD (Sigma) from cabbage. The reaction products were analyzed by thin-layer chromatography (TLC). Briefly, $20 \mu \mathrm{l}$ of 1 butanol was added to the above reaction mixes $(20 \mu \mathrm{l})$, followed by vigorous vortex mixing for $30 \mathrm{~s}$ and centrifugation $(10,000 \times \mathrm{g}, 1 \mathrm{~min})$. The upper lipid extract layer $(5 \mu \mathrm{l})$ was loaded onto a plastic-backed silica gel G60 plate without fluorescent indicator (Sigma) and air-dried for 20 min. TLC was performed either with chloroformmethanol-water-acetic acid $(45 / 45 / 10 / 1$ by vol.) when BODIPY-PC was used as the substrate, or with chloroformmethanol-acetic acid (60/20/1 by vol.) when NBD-PE, NBDPS, or NBD-SM used as the substrates. For some experiments, an apolar solvent (n-hexane (70): diethyl ether (30): acetic aid (4)) was used. Fluorescence was detected and quantified using a Typhoon 9410 laser scanner.

\section{Subcellular fractionation}

$V$. anguillarum cells were fractionated as described previously [6] and the subcellular location of Plp determined. Briefly, $100 \mathrm{ml} \mathrm{NSS-washed} \mathrm{overnight} \mathrm{grown}$ bacterial cells were resuspended in $10 \mathrm{ml}$ of ultrapure water for $20 \mathrm{~min}$ to cause osmotic shock and centrifuged $\left(10,000 \times g, 5^{\circ} \mathrm{C}, 10 \mathrm{~min}\right)$ to collect the periplasmic fraction (the supernatant). The remaining pellets were washed twice with ultrapure water and lysed by sonication (four cycles at $35 \%$ power for $20 \mathrm{~s}$, then allowed to cool for $1 \mathrm{~min})$. The sonicated cells were centrifuged $\left(10,000 \times \mathrm{g}, 5^{\circ} \mathrm{C}, 20 \mathrm{~min}\right)$ to remove cell debris and any unlysed cells, and the supernatant cell lysate was separated by ultracentrifugation $\left(200,000 \times g, 1 \mathrm{~h}, 4^{\circ} \mathrm{C}\right)$ to yield the cytosolic (supernatant) and membrane (pellet) fractions. The membrane fraction was treated with $1 \%$ Sarkosyl to obtain Sarkosyl-soluble (inner membrane) and -insoluble (outer membrane) fractions. Protein concentration in various fractions was measured using $\mathrm{BCA}$ protein determination kit (Pierce).

\section{Preparation of polyclonal antibody}

Truncated Plp protein was over-expressed and purified to serve as the antigen to create polyclonal antibody against Plp. Briefly, primer Pm212 and Pm213 (listed in Table 3) were used to amplify central portion of the $p l p$ gene, which encodes the truncated Plp protein (amino acid 93 to 293). PCR product was ligated into PQE30UA vector (QIAGEN), and transformed into E. coli M15 and transformants were selected on LB10 agar containing 
kanamycin and ampicillin. Plasmid DNA was purified and the sequence confirmed by DNA sequencing. Protein purification was performed under denaturing conditions according to the instructions of the manufacturer (QIAGEN, USA) and protein purity was determined by SDS-PAGE and Coomassie blue staining. Subsequently, the purified truncated Plp was used as antigen to prepare polyclonal antibody in two New Zealand White rabbits (Charles River Lab, MA). Briefly, $1 \mathrm{ml}$ purified antigen (concentration $=100 \mu \mathrm{g} / \mathrm{ml}$ ) was vigorously mixed with $1 \mathrm{ml}$ TiterMax Gold adjuvant (Sigma) into a homogeneous suspension. About $10 \mathrm{ml}$ of blood was withdrawn from the rabbits before immunization as a control. For the first injection, antigen-adjuvant mix was subcutaneously injected at 4 sites (over each shoulder and thigh; $100 \mu \mathrm{l} / \mathrm{site}$ ). The rabbits were boosted with single injections of antigen-adjuvant $(100 \mu \mathrm{l})$ at day 28,42 , and 56 . Blood was withdrawn 7-10 days after the $2^{\text {nd }}$ and $3^{\text {rd }}$ boosts to test the titer of antiserum using the western blot analysis. Antiserum with a high titer $(>1: 10,000)$ was aliquoted and stored at $-70^{\circ} \mathrm{C}$.

\section{Sodium dodecyl sulfate-polyacrylamide gel electrophoresis (SDS-PAGE) and Western blot analysis}

Purified proteins or other protein samples were separated in 10\% SDS-polyacrylamide gels. Prestained protein standards (Bio-Rad) and Laemmli sample buffer (Sigma) were used in all gels. Electrophoresis was performed at $100 \mathrm{~V}$ for $60-90 \mathrm{~min}$. Gels were stained with either Coomassie blue G-250 or silver stain (Pierce, USA) to visualize the protein bands. Alternatively, proteins were transferred to nitrocellulose membranes for western blot analysis using the mini-Protean II system (Bio-Rad). Protein transfers were performed as described by Towbin et al. [42] at $100 \mathrm{~V}$ for $1 \mathrm{~h}$. Nitrocellulose membranes were blocked with the addition of $5 \%$ skim milk. Detection of specific protein bands was accomplished by reacting the blot with the 1:5000 diluted antiPlp antibody, followed by the addition of the secondary antibody goat anti-rabbit IgG conjugated with peroxidase, and then developed by TMB Development Liquid (Sigma, USA).

\section{DNA sequence and analysis}

All DNA sequencing was done at the URI Genomics and Sequencing Center (University of Rhode Island, Kingston, RI), using an ABI 3170xl Genetic Analyzer unit (Applied Biosystems). Multiple alignment and phylogenic tree were analyzed using the Clustal-W method in DNA-STAR Lasergene7 program.

\section{Fish infection studies}

Various $V$. anguillarum strains were tested for virulence with rainbow trout (Oncorhynchus mykiss) by intraperitoneal
(IP) injection as described by Mou et al. [32]. Briefly, $V$. anguillarum cells grown in LB20 supplemented with appropriate antibiotics for $22 \mathrm{~h}$ at $27^{\circ} \mathrm{C}$ were harvested by centrifugation $\left(9,000 \times g, 5 \mathrm{~min}, 4^{\circ} \mathrm{C}\right)$, washed twice in NSS, and

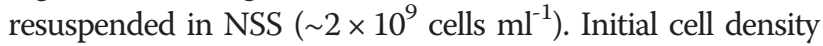
was estimated by measurement of optical density at $600 \mathrm{~nm}$. The actual cell density of NSS suspensions was determined by serial dilution and spot plating. All fish were examined prior to the start of each experiment to determine that they were free of disease or injury. Fish were anesthetized with tricaine methanesulfonate (Western Chemical, Ferndale, WA), with $100 \mathrm{mg} / \mathrm{L}$ for induction and $52.5 \mathrm{mg} / \mathrm{L}$ for maintenance. $V$. anguillarum strains were IP-injected into fish in $100 \mu \mathrm{l}$ NSS vehicle. Fish that were between 15 and $25 \mathrm{~cm}$ long were injected with bacteria diluted with NSS at various doses or NSS only as negative control. Five fish were used for each experimental group. Fish inoculated with different bacterial strains were maintained in separate 10-gallon tanks with constant water flow $(200 \mathrm{ml} / \mathrm{min})$ at $19 \pm 1^{\circ} \mathrm{C}$. The tanks were separated to prevent possible crosscontamination. Death due to vibriosis was determined by the observation of gross clinical signs and confirmed by the recovery and isolation of $V$. anguillarum cells resistant to the appropriate antibiotics from the head kidney of dead fish. The presence of the appropriate strains was tested by PCR analysis. Observations were made for 14 days. All fish used in this research project were obtained from the URI East Farm Aquaculture Center. All fish infection protocols were reviewed and approved by the University of Rhode Island Institutional Animal Care and Use Committee (URI IACUC reference number AN06-008-002; protocols renewed 14 January 2013).

\section{Competing interests}

The authors declare that they have no competing interest.

\section{Authors' contributions}

$L L, X M$ and DRN designed the study. XM and $L L$ created the strains used in this study. $L L$ and $X M$ performed all the assays. $L L, X M$ and DRN wrote the paper. Formatting of the paper was done by XM and DRN. All authors have read and approved the final version of manuscript.

\section{Acknowledgements}

This work was supported by the National Research Initiative of the USDA Cooperative State Research, Education, and Extension Service, grant no. 2008-35204-04605, awarded to D.R.N.

This research was based in part upon work conducted using the Rhode Island Genomics Sequencing Center, which is supported in part by the National Science Foundation under EPSCoR grant 0554548.

We thank Dr. Terence Bradley and lan Jaffe for their generous help and for supplying the rainbow trout used in this research. We thank Shelby Hillman for her assistance with the fish infection experiment.

\section{Author details}

${ }^{1}$ Department of Cell and Molecular Biology, University of Rhode Island, 120 Flagg Rd., Kingston, RI 02881, USA. ${ }^{2}$ College of Ocean and Earth Sciences, Xiamen University, Xiamen 361102, China. ${ }^{3}$ Present address: Massachusetts General Hospital / Harvard Medical School, 65 Landsdowne St. PRB 425, Cambridge, MA 02139, USA. 
Received: 12 August 2013 Accepted: 20 November 2013

Published: 27 November 2013

\section{References}

1. Austin B, Austin DA: Bacterial fish pathogens: disease of farmed and wild fish. In Praxis Publishing Co. Fifthth edition. New York, NY: Springer; 2012

2. Denkin SM, Nelson DR: Induction of protease activity in Vibrio anguillarum by gastrointestinal mucus. App/ Environ Microbio/ 1999, 65(8):3555-3560.

3. Toranzo AE, Barja JL: Virulence factors of bacteria pathogenic for coldwater fish. Annu Rev Fish Dis 1993, 3:5-36.

4. Egidius E: Vibriosis: Pathogenicity and pathology. Aquaculture 1987, 7:15-28.

5. Denkin SM, Nelson DR: Regulation of Vibrio anguillarum empA metalloprotease expression and its role in virulence. Appl Environ Microbiol 2004, 70(7):4193-4204.

6. Garcia T, Otto K, Kjelleberg S, Nelson DR: Growth of Vibrio anguillarum in Salmon Intestinal Mucus. Appl Environ Microbiol 1997, 63(3):1034-1039.

7. Hirono I, Masuda T, Aoki T: Cloning and detection of the hemolysin gene of Vibrio anguillarum. Microb Pathog 1996, 21(3):173-182.

8. Rock $J$, Nelson DR: Identification and characterization of a hemolysin gene cluster in Vibrio anguillarum. Infect Immun 2006, 74(5):2777-2786.

9. Li L, Rock JL, Nelson DR: Identification and characterization of a repeat-intoxin gene cluster in Vibrio anguillarum. Infect Immun 2008, 76(6):2620-2632.

10. Di Lorenzo M, Stork M, Tolmasky ME, Actis LA, Farrell D, Welch TJ, Crosa LM, Wertheimer AM, Chen Q, Salinas P, et al: Complete sequence of virulence plasmid pJM1 from the marine fish pathogen Vibrio anguillarum strain 775. J Bacterio/ 2003, 185(19):5822-5830.

11. Milton DL, O'Toole R, Horstedt $P$, Wolf-Watz $H$ : Flagellin $A$ is essential for the virulence of Vibrio anguillarum. J Bacterio/ 1996, 178(5):1310-1319.

12. Daugherty S, Low MG: Cloning, expression, and mutagenesis of phosphatidylinositol-specific phospholipase C from Staphylococcus aureus: a potential staphylococcal virulence factor. Infect Immun 1993, 61(12):5078-5089.

13. Gish $W$, States DJ: Identification of protein coding regions by database similarity search. Nat Genet 1993, 3(3):266-272.

14. Flieger A, Neumeister B, Cianciotto NP: Characterization of the gene encoding the major secreted lysophospholipase A of Legionella pneumophila and its role in detoxification of lysophosphatidylcholine. Infect Immun 2002, 70(11):6094-6106.

15. Flieger A, Rydzewski K, Banerji S, Broich M, Heuner K: Cloning and characterization of the gene encoding the major cell-associated phospholipase A of Legionella pneumophila, plaB, exhibiting hemolytic activity. Infect Immun 2004, 72(5):2648-2658.

16. Molgaard A, Kauppinen S, Larsen S: Rhamnogalacturonan acetylesterase elucidates the structure and function of a new family of hydrolases. Structure 2000, 8(4):373-383.

17. Li L, Mou X, Nelson DR: HlyU is a positive regulator of hemolysin expression in Vibrio anguillarum. J Bacteriol 2011, 193(18):4779-4789.

18. Petersen TN, Brunak S, von Heijne G, Nielsen H: SignalP 4.0: discriminating signal peptides from transmembrane regions. Nature methods 2011, 8(10):785-786.

19. Lee KK, Raynard RS, Ellis AE: The phospholipid composition of Atlantic salmon, Salmo salar L., erythrocyte membranes. J Fish Biol 1989, 35:313-314.

20. Nouri-Sorkhabi MH, Agar NS, Sullivan DR, Gallagher C, Kuchel PW: Phospholipid composition of erythrocyte membranes and plasma of mammalian blood including Australian marsupials; quantitative 31P NMR analysis using detergent. Comp Biochem Physiol B Biochem Mol Biol 1996, 113(2):221-227.

21. Simon R, Priefer U, Pühler A: A broad host range mobilization system for in vivo genetic engineering: transposon mutagenesis in gram negative bacteria. Nat Biotechnol 1983, 1(9):784-791.

22. Mcgee $K$, Hörstedt $P$, Milton DL: Identification and characterization of additional flagellin genes from Vibrio anguillarum. J Bacteriol 1996, 178(17):5188-5198.

23. Miwatani T, Takeda Y, Sakurai J, Yoshihara A, Taga S: Effect of heat (Arrhenius effect) on crude hemolysin of Vibrio parahaemolyticus. Infect Immun 1972, 6(6):1031-1033.

24. Miwatani T, Sakurai J, Yoshihara A, Takeda Y: Isolation and partial purification of thermolabile direct hemolysin of Vibrio parahaemolyticus. Biken J 1972, 15(2):61-66.

25. Sakurai J, Matsuzaki A, Takeda Y, Miwatani T: Existence of two distinct hemolysins in Vibrio parahaemolyticus. Infect Immun 1974, 9(5):777-780
26. Shinoda S, Matsuoka H, Tsuchie T, Miyoshi S, Yamamoto S, Taniguchi H, Mizuguchi Y: Purification and characterization of a lecithin-dependent haemolysin from Escherichia coli transformed by a Vibrio parahaemolyticus gene. J Gen Microbiol 1991, 137(12):2705-2711.

27. Fiore AE, Michalski JM, Russell RG, Sears CL, Kaper JB: Cloning, characterization, and chromosomal mapping of a phospholipase (lecithinase) produced by Vibrio cholerae. Infect Immun 1997, 65(8):3112-3117.

28. Lee JH, Ahn SH, Kim SH, Choi YH, Park KJ, Kong IS: Characterization of Vibrio mimicus phospholipase $\mathrm{A}(\mathrm{PhI})$ and cytotoxicity on fish cell. Biochem Biophys Res Commun 2002, 298(2):269-276.

29. Zhong Y, Zhang XH, Chen J, Chi Z, Sun B, Li Y, Austin B: Overexpression, purification, characterization, and pathogenicity of Vibrio harveyi hemolysin VHH. Infect Immun 2006, 74(10):6001-6005.

30. Akoh CC, Lee GC, Liaw YC, Huang TH, Shaw JF: GDSL family of serine esterases/lipases. Prog Lipid Res 2004, 43(6):534-552.

31. Sun B, Zhang XH, Tang X, Wang S, Zhong Y, Chen J, Austin B: A single residue change in Vibrio harveyi hemolysin results in the loss of phospholipase and hemolytic activities and pathogenicity for turbot (Scophthalmus maximus). J Bacteriol 2007, 189(6):2575-2579.

32. Merino S, Aguilar A, Nogueras MM, Regue M, Swift S, Tomas JM: Cloning, sequencing, and role in virulence of two phospholipases ( $\mathrm{A} 1$ and $\mathrm{C}$ ) from mesophilic Aeromonas sp. serogroup O:34. Infect Immun 1999, 67(8):4008-4013.

33. Banerji S, Aurass P, Flieger A: The manifold phospholipases A of Legionella pneumophila - identification, export, regulation, and their link to bacterial virulence. Int J Med Microbiol 2008, 298(3-4):169-181.

34. Koo BS, Lee JH, Kim SC, Yoon HY, Kim KA, Kwon KB, Kim HR, Park JW, Park $\mathrm{BH}$ : Phospholipase $\mathrm{A}$ as a potent virulence factor of Vibrio vulnificus. Int J Mol Med 2007, 20(6):913-918.

35. Boyanovsky BB, Webb NR: Biology of secretory phospholipase A2. Cardiovasc Drugs Ther 2009, 23(1):61-72.

36. Lee KK, Ellis AE: The quantitative relationship of lethality between extracellular protease and extracellular haemolysin of Aeromonas salmonicida in Atlantic salmon (Salmo salar L.). FEMS Microbiol Lett 1989, 52(1-2):127-131.

37. Mou X, Spinard EJ, Driscoll MV, Zhao W, Nelson DR: H-NS is a Negative Regulator of the Two Hemolysin/Cytotoxin Gene Clusters in Vibrio anguillarum. Infect Immun 2013, 81(10):3566-3576.

38. Vaatanen P: Microbiological studies in coastal waters of the Northern Baltic Sea. I. Distribution and abundance of bacteria and yeasts in the Tvarminne area. Walter Andre Nottback Found Sci Rep 1976, 1:1-58.

39. Varina M, Denkin SM, Staroscik AM, Nelson DR: Identification and characterization of Epp, the secreted processing protease for the Vibrio anguillarum EmpA metalloprotease. J Bacterio/ 2008, 190(20):6589-6597.

40. Mårdén P, Tunlid A, Malmcrona-Friberg K, Odham G, Kjelleberg S: Physiological and morphological changes during short term starvation of marine bacterial islates. Arch Microbio/ 1985, 142(4):326-332.

41. Jovel SR, Kumagai T, Danshiitsoodol N, Matoba Y, Nishimura M, Sugiyama $M$ : Purification and characterization of the second Streptomyces phospholipase $\mathrm{A} 2$ refolded from an inclusion body. Protein Expr Purif 2006, 50(1):82-88.

42. Towbin H, Staehelin T, Gordon J: Electrophoretic transfer of proteins from polyacrylamide gels to nitrocellulose sheets: procedure and some applications. Proc Natl Acad Sci U S A 1979, 76(9):4350-4354.

doi:10.1186/1471-2180-13-271

Cite this article as: Li et al:: Characterization of Plp, a phosphatidylcholinespecific phospholipase and hemolysin of Vibrio anguillarum. BMC Microbiology 2013 13:271. 